\title{
Interparietal Herniation: A Rare Cause of Intestinal Obstruction
}

\author{
Bulent Gungor $^{\mathrm{a}, \mathrm{b}}$, Koray Topgul ${ }^{\mathrm{a}}$, Mehmet Bilgin ${ }^{\mathrm{a}}$, Zafer Malazgirt ${ }^{\mathrm{a}}$
}

\begin{abstract}
An interparietal hernia is a rare form of hernia seen in the inguinal region. Its pathogenesis is not well understood. It frequently causes intestinal obstruction. We presented a case of interparietal herniation, who presented with acute symptoms and signs of intestinal obstruction. The male patient was referred to our department with acute signs of intestinal obstruction for three days. His physical examination revealed acute abdomen and intestinal obstruction. The ultrasound and computed tomography depicted an intra-abdominal mass of unknown origin. At operation, a loop of ileum was found incarcerated in an interparietal hernia. Reduction, resection and anastomosing of the segment were facilitated. The preperitoneal type of defect was closed with sutures. Interparietal hernias are rare, and represent a problem in the differential diagnosis of conditions functional in the inguinal region. It is more frequent in the males, and mostly presents with intestinal obstruction. Preoperative diagnosis of obstructing interparietal hernia is difficult. Once considered, its diagnosis and treatment is straightforward.
\end{abstract}

Keywords: Interparietal hernia; Incarceration; Intestinal obstruction; Computed tomography; Inguinal hernia

\section{Introduction}

Interparietal hernias are quite rare hernias occurring at anterior abdominal wall at various anatomical (parietal) plans in the inguinal region. Since it is a rare condition, it is generally

Manuscript accepted for publication August 25, 2010

${ }^{a}$ Ondokuz Mayis University, Faculty of Medicine, Department of Surgery, Samsun, Turkey

${ }^{\mathrm{b}}$ Corresponding author: Ondokuz Mayis University, Faculty of Medicine, Department of Surgery, 55139 Samsun, Turkey.

Email: bgungor@omu.edu.tr

doi:10.4021/jmc38w reported as sporadic cases, most of which have been in children. Its significance is that it frequently presents as a case of 'intestinal obstruction of unknown origin'. We, herewith, reviewed such a case of acutely obstructing interparietal hernia in an adult.

\section{Case Report}

A 30-year-old male had applied to another center with complaints of diffuse abdominal pain, nausea, vomiting and constipation, all of which were lasting for three days. The abdominal ultrasound (US) had demonstrated a mass pressing on the urinary bladder, which was thought to be a tumor originating from the bladder itself or from neighboring intraabdominal structures. However, the cystoscopy had been normal, and revealed no signs of neoplasm or calculus. During his follow-up, the pain had become more intense, and physical examination showed signs of acute abdomen. The patient was referred to our department. At physical examination of the patient after admission, we detected abdominal distension with muscular guarding and rebound tenderness in all quadrants. The bowel sounds were hypoactive. His laboratory tests were as follows: hemoglobin $12.7 \mathrm{~g} / \mathrm{mm}^{3}$,

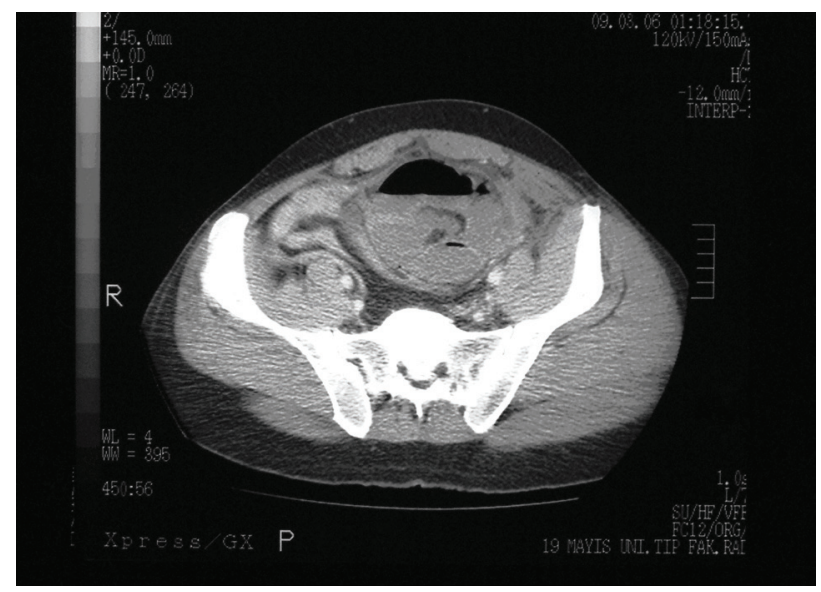

Figure 1. Preoperative CT of the patient depicted edematous small bowel loops encased in a sac. 


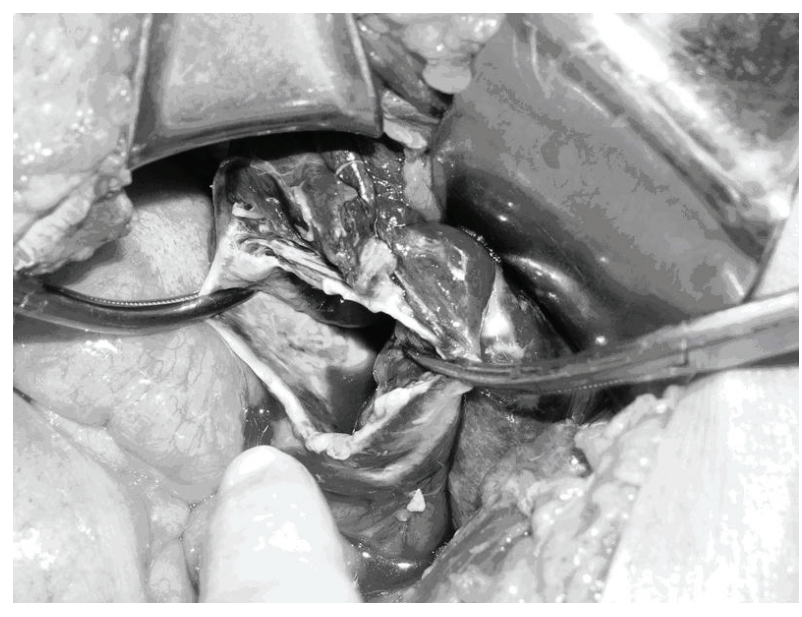

Figure 2. The midline infraumblical incision with right $(R)$ and left $(L)$ rectus muscles retracted. The peritoneal sac extended downward and sideward extraperitoneally.

hematocrit $36.4 \%$, leukocyte $11,800 / \mathrm{mm}^{3}$, platelets $194,000 /$ $\mathrm{mm}^{3}$, Na $135 \mathrm{mEq} / \mathrm{L}, \mathrm{K} 3.8 \mathrm{mEq} / \mathrm{L}, \mathrm{Cl} 102 \mathrm{mEq} / \mathrm{L}$. His liver function tests were normal. We performed an abdominal US, which demonstrated distended intestinal loops in the abdomen, and a mass of edematous intestines located in the lower right iliac fossa. The computed tomography of the abdomen defined distended jejunal loops, and helical torsion of ileal segments located in the rectovesical fossa. The cecum and the rest of colon were normal in size. The characteristic helical torsion of ileum was interpreted as a sign of internal herniation, however its cause remained unclear (Fig. 1).

The patient undertook emergency operation with a diagnosis of acute abdomen and incarcerated intra-abdominal herniation of unknown origin. Through a lower midline incision we explored the abdominal cavity. We found that a thirty-centimeter loop of ileum, about $80 \mathrm{~cm}$ proximal from the ileocecal valve, was incarcerated in a peritoneal recession in the anterior parietal peritoneum. The peritoneal sac enveloping the edematous intestine was located in the retromuscular space posterior to the right rectus muscle. The level of herniation was at about one-third of the distance from the symphysis pubis to the umbilicus. We could not determine whether the point of recession had any relation with the semicircular line. However, we did know that it did not pass through the transversalis fascia, and was definitely not a spigelian hernia. We considered that this was a preperitoneal type of interparietal hernia (Fig. 2). We reduced the incarcerated segment of ileum, which was inflamed, edematous and patchy with ecchymosed areas (Fig. 3). We resected this segment and accomplished an end-to-end anastomose. We pulled back the sac and excised it. We closed the defect with en bloc interrupted polypropylene sutures.

The patient had a remarkable recovery in the postoperative period, and was discharged on the 4th postoperative day.

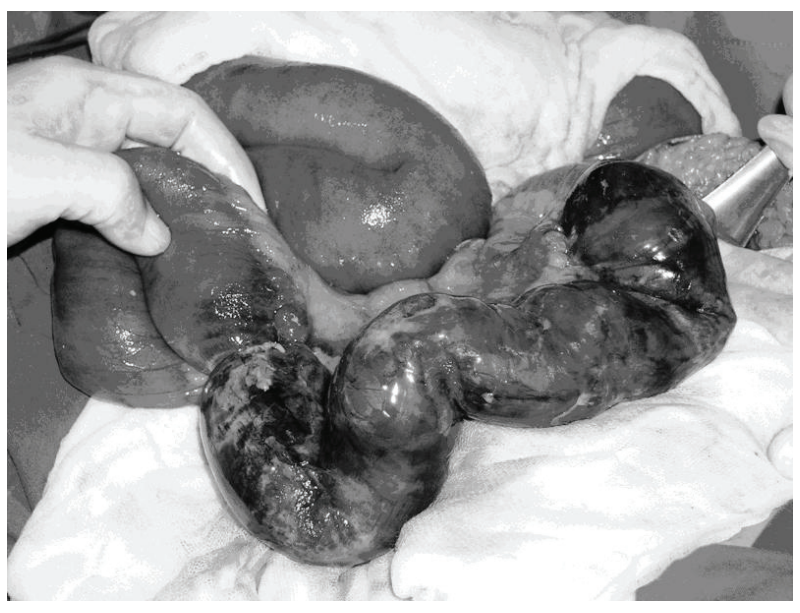

Figure 3. Reduction of incarcerated hernia revealed a $30 \mathrm{~cm}$ loop of ischemic and inflamed intestine.

He was free of any symptoms at his follow-up at six months.

\section{Discussion}

Bartolin first described interparietal hernia in 1661 [1]. Its definition has not changed since then, however, three subtypes have been described recently. The three subtypes are preperitoneal (between peritoneum and transversalis fascia), interstitial (between transversalis fascia and transverse, internal oblique or external oblique muscles), and superficial (between external oblique and skin or within aponeuroses of the inguinal region) [2]. Lower and Hicken [3] reported in their series, which is still the largest published one, that the interparietal hernias among all inguinal hernias should be as frequent as $0.01-1.6 \%$. They also commented that the interstitial subtype comprised of $60 \%$ of the cases, while the other two subtypes occurred $29 \%$ each. It is reported that the interparietal hernia is predominant in males [1].

The interparietal hernias are frequently confused with inguinal hernias. The diagnosis is usually determined during the operation, as it was the case in our patient. Koot [4] discussed whether the interparietal hernias, which frequently presents with small bowel obstruction and appears at a level above inguinal ligament, are a rare variation of inguinal hernias. In the case of closed vaginal process and intact internal ring, the interparietal hernia should be considered as a preperitoneal type. If the hernia has past through the internal ring, it is then an interstitial hernia. However, its high incidence in children and adult males suggests a relationship between the etiopathogenesis of interparietal hernia and the embryological descent of the testis, an issue that is not fully understood.

The biggest problem with the interparietal hernia is that 
its preoperative diagnosis is seldom, if ever. The preoperative imaging techniques play a significant role in naming of the condition. The computed tomography (CT) is the method of choice in the differential diagnosis, which can exclude the presence of an obstructing tumor. However, it is reported that both $\mathrm{CT}$ and herniography are not successful in differentiating the different types of inguinal hernia $[5,6]$. In our case the CT depicted very well that the mass was not a tumor, however it did not differentiate it as an interparietal hernia. It seems that the magnetic resonance imaging (MRI) is more sensitive and specific in differentiating the inguinal anatomy [7]. The intraperitoneal scintigraphy has also been utilized in the diagnosis of inguinal conditions [8]. Although it is generally accepted that US does not yield in a definite diagnosis due to tissue factors [9], recent studies have reported successful results with the US in differentiating hernia types in the inguinal region [10].

We conclude that surgeons may sometimes come across with interparietal hernias either in the form of an odd inguinal hernia or as a case of acute intestinal obstruction of an unknown origin. Surgeons may reach to a correct preoperative diagnosis if they consider it when they have a case of unknown origin. The emergency approach to repair is straightforward once it is diagnosed.

\section{References}

1. Reddy KM, Stellakis MLC, Khaliq T, Fiennes AGTW, Interparietal hernia mimicking malignant small bowel obstruction. Hernia 1999; 3:37-8.

2. Zollinger RM JR, Claasification of ventral and groin hernias. In: Fitzgibbons RJ, Greenburg AG (eds) Nyhus \& Condon's Hernia Lippincott Williams \& Wilkins, Philadelphia, pp 71-9; 2002.

3. Lower WE, Hicken NF. Interparietal Hernias. Ann Surg 1931;94(6):1070-1087.

4. Koot VC, de Jong JR, Perre CI. The interparietal hernia: a rare variant of an inguinal hernia. Eur J Surg 1997;163(2):153-155.

5. Hojer AM, Rygaard H, Jess P. CT in the diagnosis of abdominal wall hernias: a preliminary study. Eur Radiol 1997;7(9):1416-1418.

6. Loftus IM, Ubhi SS, Rodgers PM, Watkin DF. A negative herniogram does not exclude the presence of a hernia. Ann R Coll Surg Engl 1997;79(5):372-375.

7. van den Berg JC, de Valois JC, Go PM, Rosenbusch G. Dynamic magnetic resonance imaging in the diagnosis of groin hernia. Invest Radiol 1997;32(10):644-647.

8. Gupta SM, Bagga S, Gelfman N, Margules R. Demonstration of subclinical inguinal hernia by peritoneal scintigraphy. Clin Nucl Med 1997;22(6):409-410.

9. Truong SN, Jansen M. Diagnostic imaging in the evaluation and management of abdominal wall hernia. In: Fitzgibbons RJ, Greenburg AG (eds) Nyhus \& Condon's Hernia Lippincott Williams \& Wilkins, Philadelphia,pp 81-94; 2002.

10. Jamadar DA, Jacobson JA, Morag Y, Girish G, Ebrahim F, Gest T, Franz M. Sonography of inguinal region hernias. AJR Am J Roentgenol 2006;187(1):185-190. 